\title{
Heroin-Induced Reinstatement is Specific to Compulsive Heroin Use and Dissociable from Heroin Reward and Sensitization
}

\author{
Magalie Lenoir' and Serge H Ahmed*, \\ 'Laboratoire de Neuropsychobiologie des Désadaptations, University Victor-Segalen Bordeaux2, CNRS-UMR 554I, Bordeaux, France
}

\begin{abstract}
Increased drug availability can precipitate a rapid transition to compulsive drug use in both vulnerable humans and laboratory animals. Recent studies have shown that despite equivalent levels of psychomotor sensitization, only rats with prolonged, but not limited, access to cocaine self-administration respond to the priming effects of cocaine on drug seeking, as measured in a within-session reinstatement model of drug craving. In this model, drug seeking is first extinguished and then reinstated by non-contingent presentations of the drug alone in the absence of response-contingent stimuli. Here, we assessed the generality of this observation in rats with daily short (I h, ShA) vs long access ( $6 \mathrm{~h}, \mathrm{LgA})$ to i.v. heroin self-administration. As expected, heroin intake by $\mathrm{LgA}$ rats $(n=24)$ increased over time to become excessive compared to heroin intake by ShA rats $(n=24)$. After escalation, LgA rats tended to be less sensitive to heroin-induced locomotion (7.5-30 $\mu$ g, i.v.) than ShA rats. In contrast, only LgA rats, not ShA rats, responded to the priming effects of heroin, as measured by the ability of heroin alone $(7.5-30 \mu$ g, i.v.) to reinstate extinguished drug-seeking behavior. Finally, during the course of heroin intake escalation, a large proportion of LgA rats developed self-injury (mostly targeting the nails and digit tips of the forepaws), a negative consequence not seen in ShA rats. This study reproduces and extends previous research on compulsive cocaine use by showing that heroin-induced reinstatement is also specific to compulsive drug use and dissociable from heroin-induced reward and psychomotor sensitization.

Neuropsychopharmacology (2007) 32, 616-624. doi:I 0.1038/sj.npp. I30I083; published online 26 April 2006
\end{abstract}

Keywords: addiction; dependence; self-administration; tolerance; sensitization; craving; self-injury

\section{INTRODUCTION}

A critical goal of drug addiction research is to understand the differences between controlled and compulsive drug use, the latter being diagnostic of addiction (Koob et al, 1998). Based on previous work using continuous access to drug self-administration (Deneau et al, 1969; Johanson et al, 1976; Bozarth and Wise, 1985; Wolffgramm, 1991), we and others have recently developed and begun to validate an animal model of the transition to compulsive drug use (see for review Ahmed, 2005). Differential access to intravenous cocaine or heroin self-administration produces two patterns of drug intake. With $1 \mathrm{~h}$ of access per session (short access or ShA), drug intake is low and stable over time. In contrast, with 6 or more hours of access per session (long access or $\operatorname{LgA}$ ), drug intake gradually escalates and becomes excessive compared to control levels (Ahmed and Koob, 1998; Ahmed

*Correspondence: Dr SH Ahmed, Laboratoire de Neuropsychobiologie des Désadaptations, University Victor-Segalen Bordeaux2, CNRS-UMR 554I, 33076 Bordeaux, France, Tel: + 33557 57I566, Fax: + 33556900 278, E-mail: sahmed@Inpb.u-bordeaux2.fr

Received 20 December 2005; revised 3 March 2006; accepted 6 March 2006

Online publication: 16 March 2006 at http://www.acnp.org/citations/ Npp03 $1606050753 /$ default.pdf et al, 2000; Mantsch et al, 2001; Paterson and Markou, 2003; Walker et al, 2003; Roth and Carroll, 2004; Ferrario et al, 2005; Liu et al, 2005). Once established, escalated levels of drug consumption can persist for several weeks, despite reduced drug availability (Ahmed and Koob, 1999).

The differences between stable and escalating patterns of drug consumption have been proposed to model the differences between controlled and compulsive drug use (Ahmed and Koob, 1998). This interpretation is supported by a series of behavioral investigations showing that $\operatorname{LgA}$ rats can be considered as genuine drug-addicted individuals compared to ShA rats (Ahmed, 2005). First, LgA rats are more motivated than ShA rats to work to obtain cocaine or heroin, as shown by increased breakpoints in a progressive ratio schedule of drug self-administration (Paterson and Markou, 2003; Ahmed, 2005; but see, Liu et al, 2005). Second, LgA rats have a greater difficulty of abstaining from seeking the drug than ShA rats during extinction. LgA rats persist longer than ShA rats in responding on the drugpaired lever despite the fact that this behavior is not rewarded (ie, they present a resistance to extinction; Ahmed et al, 2000). Third, after prolonged exposure to drug selfadministration, $\operatorname{LgA}$ rats become less sensitive to a danger signal that normally deters animals from seeking the drug during extinction (Vanderschuren and Everitt, 2004). This 
observation suggests that $\operatorname{LgA}$ rats accept to take increased risks to seek the drug and that their drug-seeking behavior has become inflexible (see also, Wolffgramm, 1991; Heyne and Wolffgramm, 1998). Finally, LgA rats, but not ShA rats, develop a persistent decrease in brain reward function, a phenomenon that would explain why addicted individuals neglect alternative rewarding activities in favor of drug use (Ahmed et al, 2002, 2005). In support of this hypothesis, the demand for drug consumption is inelastic in $\operatorname{LgA}$ rats compared to ShA rats, suggesting a blunted responsiveness to natural substitutes of drug reward (Ahmed, 2005).

Overall, these findings show that rats with extended access to drug self-administration develop all the major behavioral signs of drug dependence. Several different mechanisms have been advanced to explain the transition to drug dependence, including psychomotor sensitization (Robinson and Berridge, 1993) and allostasis-induced reward tolerance (Koob and Le Moal, 2001). Although current evidence favors a role for reward allostasis (Ahmed and Koob, 2005), the contribution of psychomotor sensitization to compulsive drug use is still a subject of debate (Zernig et al, 2004 and associated commentaries). According to the sensitization hypothesis, the neuroadaptations involved in psychomotor sensitization would be homologous to those involved in compulsive drug use and relapse (Robinson and Berridge, 1993). Current neurobiological research on relapse to drug seeking in animals provides some support for this hypothesis (Kalivas, 2005; Shaham and Hope, 2005), although there is also evidence for some neurobiological dissociations between psychomotor sensitization and drug-seeking behavior (Shaham and Hope, 2005).

We recently began to test the validity of the sensitization hypothesis of drug addiction in animals with differential access to cocaine self-administration (Ben-Shahar et al, 2004; Ahmed and Cador, 2006). We concurrently assessed the ability of cocaine to induce stimulation of locomotion and to reinstate drug seeking after extinction in both ShA rats and LgA rats. Reinstatement of extinguished drug seeking is considered as a valid animal model of drug craving and relapse (Shaham et al, 2003; See et al, 2003; Weiss et al, 2001). After 45 min of extinction of cocaine selfadministration, all animals were challenged with different doses of cocaine $(0.125-1 \mathrm{mg}$, i.v.) in the absence of response-contingent stimuli. This within-session reinstatement procedure allowed one to measure the priming or reinstating effects of the drug, without the potential confounding influence of unconditioned and/or conditioned sensory reinforcement (eg, Berlyne, 1969; Tapp, 1969; Gomer and Jakubczak, 1974; Robbins and Koob, 1978). The sensitization hypothesis predicts that LgA rats should be more responsive than ShA rats to both the psychomotor and priming effects of cocaine. Contrary to this prediction, however, we found that despite identical levels of psychomotor sensitization, only LgA rats, not ShA rats, responded to the reinstating effects of cocaine. The lack of cocaine-induced reinstatement in ShA rats shows that below some duration of exposure to cocaine selfadministration ( $\leqslant 1 \mathrm{~h} /$ day), rats can become sensitized to its psychomotor effects without becoming responsive to its priming effects. Thus, cocaine-induced reinstatement is an acquired behavior specific to compulsive cocaine use and dissociable from cocaine-induced reward and psychomotor sensitization. This conclusion is consistent with previous research on individual rats with spontaneously high levels of cocaine consumption (Sutton et al, 2000; Baker et al, 2001).

The present study was designed to extend this conclusion to rats with differential access to i.v. heroin self-administration. As with cocaine, it has been hypothesized that the neuroadaptations involved in heroin sensitization would be the same to those mediating the priming effects of heroin, although in the case of heroin, there is as yet no direct neurobiological evidence supporting this notion (Shaham and Hope, 2005). This hypothesis predicts that rats with prolonged access to heroin should be more sensitized than rats with limited access to both the psychomotor and priming effects of heroin. To test this prediction, we compared the efficacy of heroin to concurrently induce stimulation of locomotion and reinstatement of drugseeking behavior in rats with differential access to heroin self-administration. After escalation of heroin intake by LgA rats, all animals were tested with different heroin doses $(7.5-30 \mu \mathrm{g}, \mathrm{i} . \mathrm{v}$.$) in a within-session reinstatement model of$ drug-induced craving (Ahmed and Cador, 2006). All tests were conducted in the environment paired with heroin selfadministration. This experimental design uniquely allowed us to study how the psychomotor (locomotion), rewarding (self-administration), and priming (reinstatement of extinguished responding) effects of heroin are differentially altered during the transition to compulsive heroin consumption.

\section{MATERIALS AND METHODS}

\section{Subjects}

Forty-eight naïve, young adult, male, Wistar (Han) rats were used, weighing 216-266 g before surgery (Charles River, France). Rats were housed in groups of two or three and were maintained in a light- (12-h reverse light-dark cycle; lights on at 2130) and temperature-controlled vivarium $\left(23^{\circ} \mathrm{C}\right)$. All behavioral testing occurred during the dark phase of the light-dark cycle. Food and water were freely available in the home cages. All experiments were carried out in accordance with institutional and international standards of care and use of laboratory animals (UK Animals (Scientific Procedures) Act, 1986; and associated guidelines; the European Communities Council Directive (86/609/EEC, 24 November 1986) and the French Directives concerning the use of laboratory animals (décret 87-848, 19 October 1987)).

\section{Apparatus}

Twelve identical operant chambers $(30 \times 40 \times 36 \mathrm{~cm})$ were used for all behavioral training and testing (Imétronic, France). All chambers were located away from the colony room in a dimly lit room. They were individually enclosed in wooden cubicles equipped with a white noise speaker $(45 \pm 6.2 \mathrm{~dB})$ for sound attenuation and an exhaust fan for ventilation. Each chamber had a stainless-steel grid floor (rod diameter: $6 \mathrm{~mm}$; inter-rod distance: $16 \mathrm{~mm}$ ) that allowed waste collection in a removable tray containing 
maize sawdust. Each chamber was constituted of two opaque operant panels on the right and left sides, and two clear Plexiglas walls on the back and front sides. Two retractable levers $(2 \times 4 \times 1 \mathrm{~cm}$; Imétronic, France) were mounted on different panels (one on the middle of the left panel, the other on the middle of the right panel). Each lever was mounted $7 \mathrm{~cm}$ above the grid floor and protruded from the wall $2 \mathrm{~cm}$ (when extended). A white light diode $(1.2 \mathrm{~cm}$ OD) was mounted $8.5 \mathrm{~cm}$ above each lever (from the center of the diode). Each lever was connected to a syringe pump (Imétronic, France) placed outside, on the top of the cubicle. To increase precision, the syringe pump was conceived to deliver drug solution in discrete fixed volumes of exactly $37 \mu$ l (with $20-\mathrm{ml}$ syringes), with one unit volume delivered within approximately $1 \mathrm{~s}$. Drug solution was delivered through a Tygon tubing (Cole Parmer) connected via a single-channel liquid swivel (Lomir Biomedical Inc., Quebec, Canada) to a cannula connector (Plastics One, Roanoke, VA) on the back of the animal. The Tygon tubing was protected by a stainless-steel spring $(0.3 \mathrm{~cm} \mathrm{ID,} 0.5 \mathrm{~cm}$ OD) (Aquitaine Ressort, France), which was suspended at the center of the chamber from the swivel tether connector. Vertical movements of the animal were compensated for by means of a counterbalancing weight-pulley device (Imétronic, France).

Each self-administration chamber was also equipped with two pairs of infrared beams $2 \mathrm{~cm}$ above the grid floor. Both pairs crossed the chamber on its length axis (Imétronic, France) and were separated from each other by $16 \mathrm{~cm}$, and from the right or left wall by $12 \mathrm{~cm}$. This placement allowed one to count the number of horizontal displacements of the animal to go to and fro between the two extremities of the length axis (cage crossings or crossovers). Operant chambers were connected to a PC via an Imétronic interface and experiments were controlled and conceived using an Imétronic software (Imétronic, France).

\section{Surgery}

Anesthetized rats (chloral hydrate, $500 \mathrm{mg} / \mathrm{kg}$ IP) (J-T Baker, The Netherlands) were prepared with silastic catheters (Dow Corning Corporation, MI) in the right jugular vein that exited the skin in the middle of the back about $2 \mathrm{~cm}$ below the scapulae (Caine et al, 1993). After surgery, catheters were flushed daily with $0.15 \mathrm{ml}$ of a sterile antibiotic solution containing heparinized saline $(280 \mathrm{IU} / \mathrm{ml})$ (Sanofi-Synthelabo, France) and ampicillin (Panpharma, France). When needed, the patency of the catheter was checked by administering $0.15 \mathrm{ml}$ of the short-acting non-barbiturate anesthetic etomidate through the catheter (Braun Medical, France).

\section{I.V. Heroin Self-Administration}

This experiment was run in two replications, about 1 year apart ( $n=24$ per replication). Locomotion could be measured only during the second replication; during the first replication, self-administration boxes were not yet fitted with infrared beams.

One week after i.v. catheterization, rats were tested for heroin self-administration during two consecutive phases: a screening phase (one session) and an escalation phase (18 sessions). There was no operant training before access to heroin self-administration in the present study. During the screening phase, rats were allowed to self-administer heroin $(15 \mu \mathrm{g}$ per unit dose delivered in a volume of $74 \mu \mathrm{l})$ during only $1 \mathrm{~h}$ after which two balanced groups with the same mean body weight (ShA rats, $300.8 \pm 2.9 \mathrm{~g}$; LgA rats, $297.0 \pm 4.0 \mathrm{~g}$ ) and mean heroin self-administration $(6.1 \pm 0.4$ injections in both groups) were formed. This 1 -day screening method of balancing groups was shown to be highly reliable in previous experiments on escalation of cocaine self-administration (Ahmed et al, 2002, 2003, 2005; Ahmed and Cador, 2006). During the escalation phase, one group had access to heroin self-administration for only $1 \mathrm{~h} /$ day (short-access or ShA rats, $n=24$ ) and the other group for $6 \mathrm{~h} /$ day (long-access or LgA rats, $n=24$ ). To speed up the escalation process, the unit dose of heroin available during the last $5 \mathrm{~h}$ of each long-access session was increased to $60 \mu \mathrm{g}$ (by increasing the injection volume to $296 \mu \mathrm{l}$ ) (Mantsch et al, 2004).

Self-administration sessions began with extension of one of the two retractable levers; the other lever remained retracted for the entire duration of the experiment (lever side was counterbalanced across rats). The first response on the lever triggered the countdown to the session ending. Subsequent responding on the lever resulted in the delivery of one unit dose of heroin and initiated a 20-s time-out period signaled by the light cue located above the lever. No non-contingent injections of heroin were given, except on rare occasions when a subject failed to respond within the first $10 \mathrm{~min}$ in which case it received two passive injections $20 \mathrm{~s}$ apart. No inactive lever was used in the present study; under our conditions, inactive responses are negligible during the maintenance of both cocaine and heroin selfadministration and are unaffected during escalation (eg, Ahmed and Koob, 1998; Ahmed et al, 2000). Self-administration sessions were run 5-6 days/week.

\section{Heroin-Induced Reinstatement of Extinguished Responding}

Heroin-induced reinstatement of extinguished drug-seeking behavior was assessed on two occasions in the selfadministration chamber: $24 \mathrm{~h}$ after self-administration sessions 11 and 17 (first replication) or sessions 12 and 18 (second replication) (Tests 1 and 2). Note that the short withdrawal period $(24 \mathrm{~h})$ allowed us to probe the subject's sensitivity to the priming effects of heroin during the maintenance of escalated levels of heroin intake. Between reinstatement tests, rats continued to self-administer heroin (1 or $6 \mathrm{~h}$ ) during 4 consecutive days. During each reinstatement test, the lever was extended but lever pressing had no programmed consequence (no contingent drug injection or light cue presentation), thereby inducing a rapid within-session extinction of heroin-seeking behavior. After $45 \mathrm{~min}$ of extinction, rats received four non-contingent doses of heroin $(0,7.5,15$, and $30 \mu \mathrm{g})$ every $45 \mathrm{~min}$ by increasing the volume of the non-contingent injection $(0,37,74$, and $148 \mu \mathrm{l}$ in that order). Note that the dose 0 corresponds to a sham injection. To signal drug delivery, the onset of each injection coincided with the noncontingent presentation of the 20-s time-out cue used during self-administration. No response-contingent light 
cue was available afterward during the 45-min inter-dose interval, however, because drugs of abuse can dramatically increase operant responding for discrete light cues in nonconditioned, drug-naïve rats (eg, Berlyne, 1969; Gomer and Jakubczak, 1974). Heroin-induced drug-seeking behavior (ie, non-reinforced lever pressing) was measured over $45 \mathrm{~min}$ after each dose. In half of the rats (12 ShA rats and $12 \operatorname{LgA}$ rats), locomotion (ie, crossovers) was also measured after each dose delivery.

\section{Drugs}

Heroin (3,6-diacetylmorphine $\mathrm{HCl}$ ) (Francopia Sanofi, France) was dissolved in 500-ml sterile bags of $0.9 \% \mathrm{NaCl}$ and kept at room temperature $\left(21 \pm 2{ }^{\circ} \mathrm{C}\right)$. Drug doses were expressed as the weight of the salt.

\section{Data Analysis}

There was no significant difference in behavioral outcomes between replications (not shown). As a result, all behavioral data were pooled and analyzed conjointly. Data were subjected to two-way mixed analyses of variance (ANOVA) with one between-subjects factor (experimental groups: ShA and LgA groups) and one within-subjects factor (selfadministration sessions, heroin doses or time intervals). All post hoc comparisons for interactions were carried out by the Newman-Keuls test. The percentages of animals that responded during reinstatement testing were analyzed using the $\chi^{2}$ test.

\section{RESULTS}

\section{Escalation of I.V. Heroin Self-Administration}

To assess the effects of the duration of access to heroin on drug intake (1 vs $6 \mathrm{~h}$ ), only the number of drug injections during the first hour was compared between ShA and LgA rats (Figure 1). This number was similar in both groups at the beginning of the escalation phase. During the escalation phase, however, the first hour heroin intake by $\operatorname{LgA}$ rats significantly rose above the level of intake by ShA rats $($ Group $\times$ Session: $\mathrm{F}[18,828]=13.57, p<0.05)$. Post hoc comparisons showed that significant differences between groups appeared from session 4 onward (Newman-Keuls, $p<0.05)$. In $\operatorname{LgA}$ rats, heroin injections during the last $5 \mathrm{~h}$ also increased from a mean of $10.3 \pm 0.7$ to $21.1 \pm 1.3$ at doses of $60 \mu \mathrm{g}(\mathrm{F}[17,391]=14.37, p<0.05)$ (Figure 1$)$.

\section{Extinction and Reinstatement of Heroin-Seeking Behavior}

In both ShA and LgA rats, heroin-seeking behavior extinguished rapidly within the first $45 \mathrm{~min}$ of each reinstatement test (Test 1: $\mathrm{F}(8,368)=33.28, p<0.05$; Test 2: $\mathrm{F}(8,368)=58.71, p<0.05)$ (Figure 2). LgA rats responded more than ShA rats during extinction (Test 1: $\mathrm{F}(1,46)=29.59, p<0.05$; Test $2: \mathrm{F}(1,46)=7.92, p<0.05)$, a result that reproduces previous findings (Ahmed et al, 2000). Nevertheless, this difference became negligible at the end of extinction, just before administration of the first heroin dose (ie, dose 0). After extinction, heroin reinstated
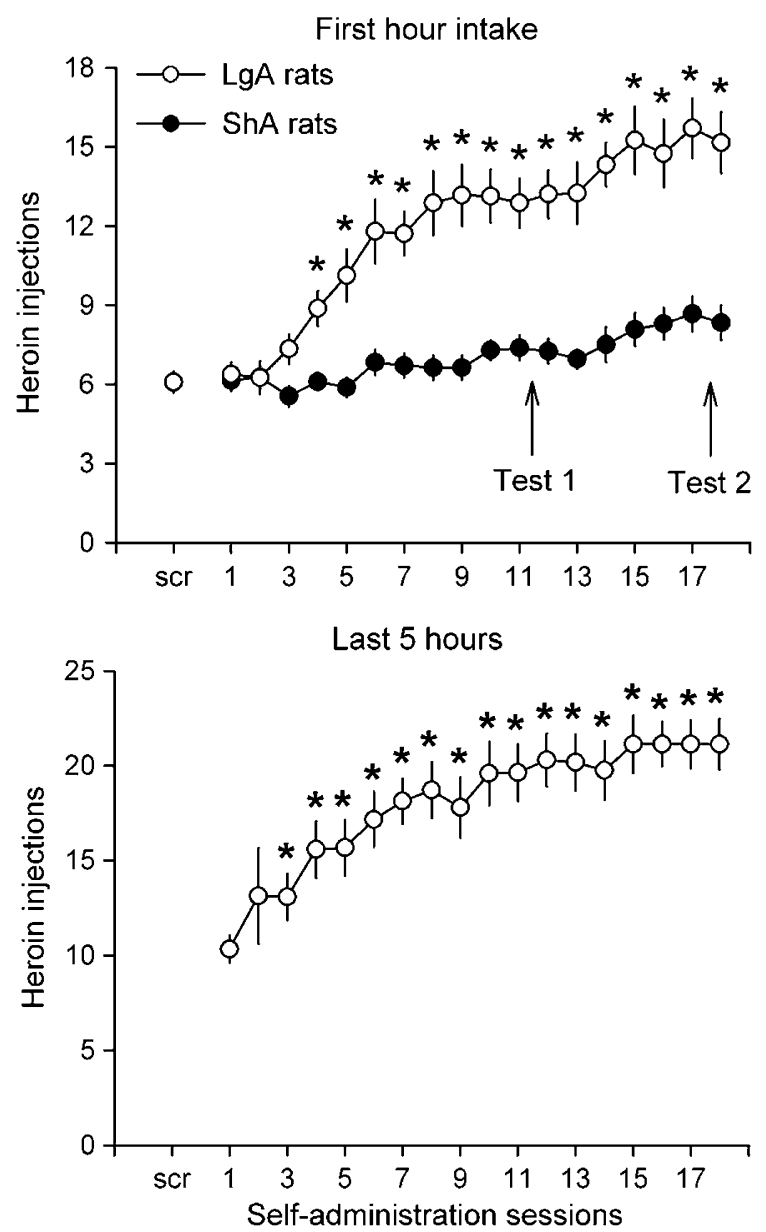

Figure I Effects of access time to heroin on the number of heroin injections during the first hour (top) and during the last $5 \mathrm{~h}$ (bottom) of each self-administration session (means \pm SEM). During the screening day (scr), all rats had access to heroin self-administration during I h ( I5 $\mu \mathrm{g}$ / injection). Then, rats were distributed into balanced groups ( $n=24$ per group) with differential access to heroin for either I h/day (ShA rats) or $6 \mathrm{~h} /$ day (LgA rats). In LgA rats, the unit dose of heroin was increased to $60 \mu \mathrm{g} /$ injection during the last $5 \mathrm{~h}$ of each 6 -h self-administration session (for additional information, see text). Vertical arrows indicate when rats were tested for reinstatement (see text for more details). *Different from ShA rats (top graph) or from the first session (bottom graph) $(p<0.05)$

drug-seeking behavior in LgA rats but not in ShA rats, a difference that was dependent on the priming dose (Test 1: $\mathrm{F}(3,138)=8.07, p<0.05$; Test $2: \mathrm{F}(3,138)=9.16, p<0.05)$ (Figure 3). Post hoc comparisons revealed that LgA rats responded more to heroin than ShA rats at the doses of 15 and $30 \mu \mathrm{g}$ during both Tests 1 and $2(p<0.05$, NewmanKeuls test). Note that identical findings were obtained when only the first $15 \mathrm{~min}$ post-injections were considered for analysis (not shown). Importantly, during all reinstatement tests, the proportion of LgA individuals that responded to heroin was greater than the proportion of ShA rats $\left(\chi^{2}=115.49\right.$, d.d.1. $\left.=1, p<0.05\right)$ (Figure 4a). An individual was considered as a heroin responder during reinstatement testing if its level of responding at the highest dose was above its level at the dose 0 by at least 1 standard deviation of the mean at the dose 0 (Test $1: 1 \mathrm{SD}=5.2$ responses; Test 2: $1 \mathrm{SD}=4.1$ responses). Assuming that responses at the dose 0 distribute normally, this statistical criterion can discriminate a responder from a non-responder with a 

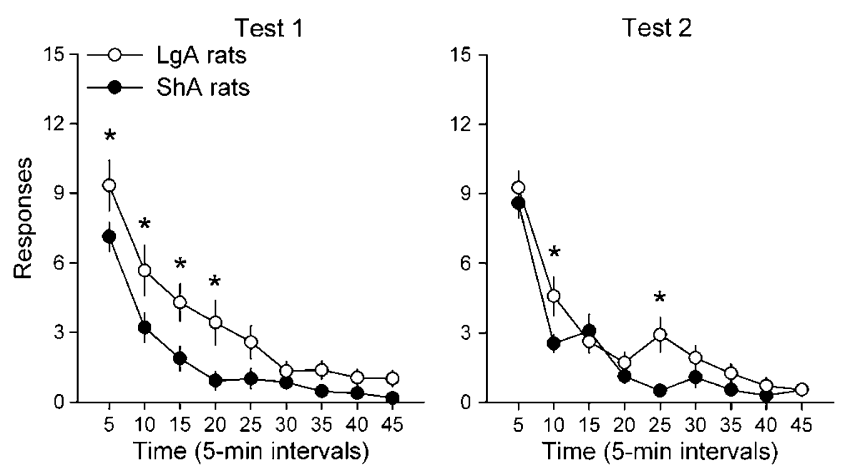

Figure 2 Within-session extinction of heroin-seeking behavior (mean$s \pm$ SEM). Heroin-seeking behavior was extinguished on two occasions: a first time, $24 \mathrm{~h}$ after self-administration session $1 \mathrm{I}$ or 12 (Test I), and a second time, $24 \mathrm{~h}$ after session 17 or 18 (Test 2). During all tests, the lever was extended but lever pressing had no programmed consequence (no response-contingent drug delivery or light cue presentation). Responding extinguished rather rapidly within the first 45 min preceding non-contingent heroin delivery. Extinction of heroin-seeking behavior was significantly slower in LgA rats than in ShA. *Different from ShA rats $(p<0.05)$.
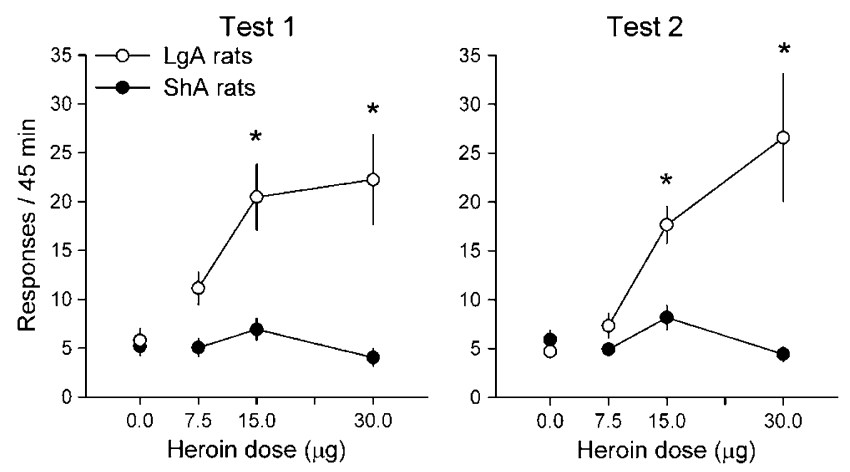

Figure 3 Heroin-induced reinstatement of previously extinguished drugseeking behavior (means \pm SEM). The reinstating effects of heroin were assessed on two occasions: a first time, $24 \mathrm{~h}$ after self-administration session II or 12 (Test I), and a second time, $24 \mathrm{~h}$ after session 17 or 18 (Test 2). During all tests, rats passively received increasing i.v. doses of heroin, one dose every $45 \mathrm{~min}$ with the first 45 -min interval corresponding to behavioral extinction (see Figure 2). The lever was extended but lever pressing had no programmed consequence (no response-contingent drug delivery or light cue presentation). *Different from ShA rats $(p<0.05)$.
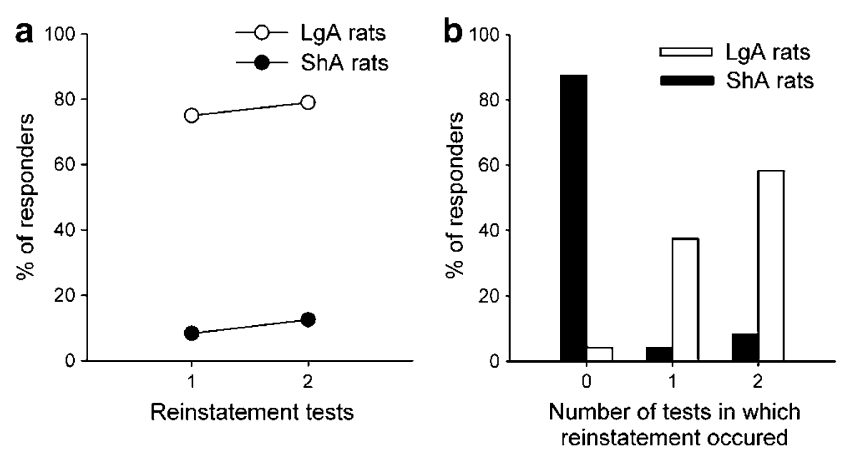

Figure 4 Percentage of rats that responded to heroin during each reinstatement test (a) and percentage of rats that responded to heroin 0,1 , or 2 times across all tests (b). An individual was considered as a heroin responder during reinstatement testing if its level of responding at the highest dose $(30 \mu \mathrm{g})$ was above its level at the dose 0 by at least I standard deviation of the mean at the dose 0 . reasonable error of about $15 \%$. Also, the proportion of rats that responded to heroin at least once across the two reinstatement tests was considerably higher in the $\operatorname{LgA}$ group (95\%) than in the ShA group (12\%) (Figure 4b).

\section{Heroin-Induced Stimulation of Locomotion}

During both reinstatement tests, heroin induced a dosedependent increase in locomotion (Test $1: \mathrm{F}(3,66)=32.28$, $p<0.05$; Test 2: $\mathrm{F}(3,66)=28.17, p<0.05)$ (Figure 5). During Test $1, \operatorname{LgA}$ rats were as sensitive as ShA rats to the psychomotor effects of heroin (Group: $\mathrm{F}(1,22)<1$; GroupDose: $F(3,66)<1)$. During Test 2, however, LgA rats responded less to the psychomotor effects of heroin than ShA rats, a difference that was dose-dependent (GroupDose: $\mathrm{F}(3,66)=2.80, p<0.05)$. Post hoc comparison showed that this difference was significant only at the $15-\mu$ g dose (Newman-Keuls, $p<0.05$ ).

\section{Body Weight Gain}

None of the groups significantly lost weight during the experiment (Figure 6a). However, body weight gain was suppressed in $\operatorname{LgA}$ rats $(8.9 \pm 3.1 \mathrm{~g})$ compared to ShA rats $(81.6 \pm 4.5 \mathrm{~g})$. As a result, the differences in absolute heroin intake between ShA and $\operatorname{LgA}$ rats reported in Figure 1 are underestimated. To circumvent this underestimation, heroin intake was normalized to body weight in all rats (Figure 6b). Note that rats were weighed every 3-4 days, which explains why there are less data points in Figure 6 than in Figure 1.

\section{Heroin-Induced Self-Injury}

During the course of heroin intake escalation, $50 \%$ of $\operatorname{LgA}$ rats (12 out of a total of 24) began to self-mutilate (median onset: 12 self-administration sessions; range: $3-18$ sessions), a maladaptive behavior not seen in ShA rats. Self-injury consisted of repetitive biting of the body extremities to the point of bleeding. The self-damaged extremities included
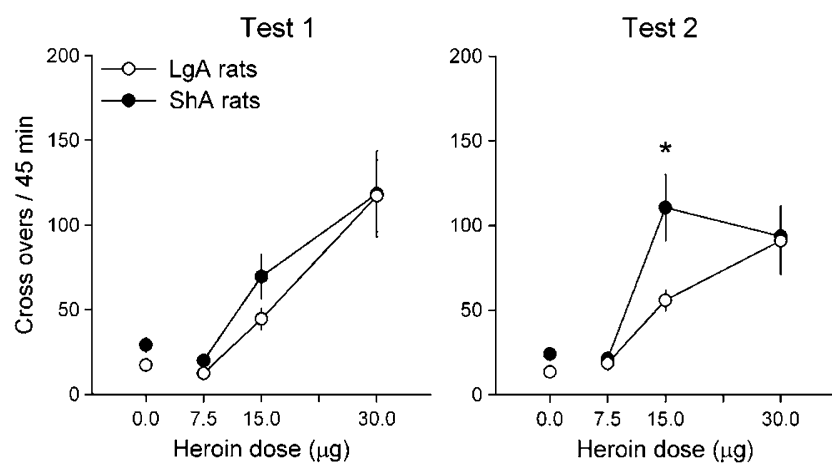

Figure 5 Effects of access time to heroin self-administration on heroininduced stimulation of locomotion during reinstatement testing (mean$s \pm S E M$ ). The psychomotor effects of heroin were assessed on two occasions in both ShA and LgA rats: a first time, $24 \mathrm{~h}$ after selfadministration session II or 12 (Test I), and a second time, $24 \mathrm{~h}$ after session 17 or 18 (Test 2). During all tests, rats passively received increasing i.v. doses of heroin, one dose every $45 \mathrm{~min}$ with the first 45 -min interval corresponding to behavioral habituation (not shown). Behavioral testing took place in the self-administration chamber $(40 \mathrm{~cm}$ in length). *Different from $\operatorname{LgA}$ rats $(p<0.05)$. 

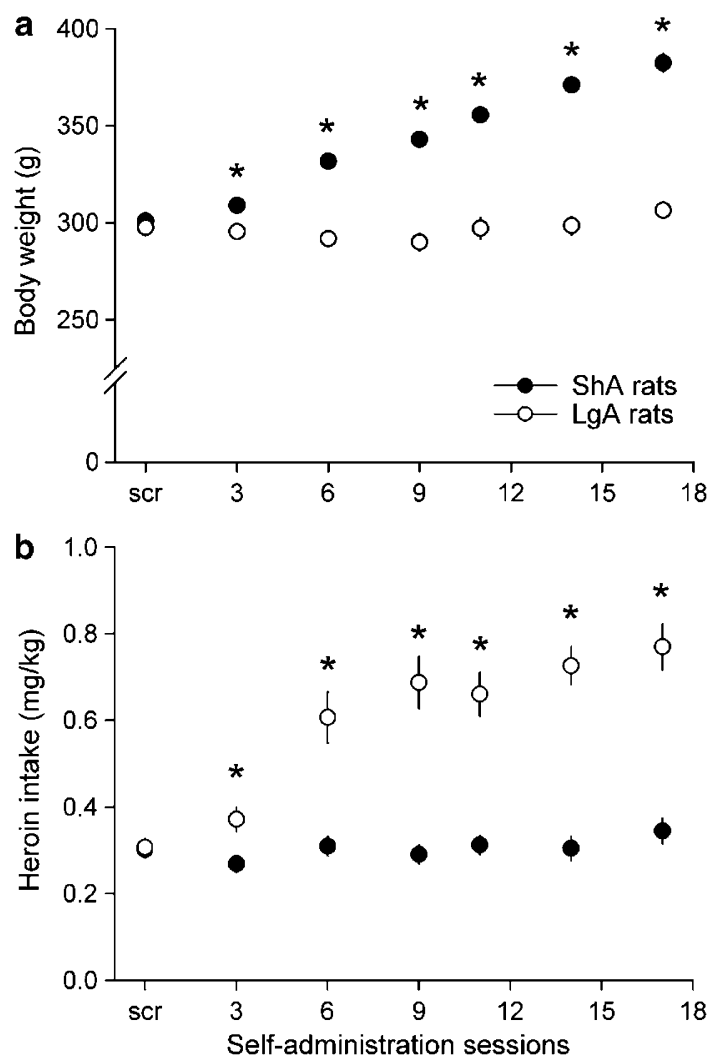

Figure 6 Effects of access time to heroin self-administration on (a) body weight gain and (b) heroin intake (means \pm SEM). All rats were weighed in the colony room 10-15 min before access to heroin self-administration. Note that body weight was measured every third or fourth day. *Different from (a) $\operatorname{LgA}$ rats or (b) ShA rats $(p<0.05)$.

the nails and digit tips of the forepaws (100\% of cases) and/ or hindpaws ( $16.6 \%$ of cases), and only very rarely, the tip of the tail ( $8.3 \%$ of cases). Self-injurious behavior occurred only during the last $5 \mathrm{~h}$ when $\operatorname{LgA}$ animals had access to the largest dose of heroin $(60 \mu \mathrm{g})$. In an attempt to divert the biting behavior away from the subject's body, rats were supplied with six daily regular chow pellets $(5 \mathrm{~g}$ each) beginning the day after observation of self-injury. Note that food pellets were available during the last $5 \mathrm{~h}$, but not during the first hour, of each long-access session of selfadministration. Supplying food abolished the incidence of self-injurious behavior but was without effect on the level or pattern of heroin intake (Group: $F(1,22)=0.04$; GroupDose: $F(18,396)=0.78)$. Finally, note that during reinstatement testing, $\operatorname{LgA}$ rats were not provided with food pellets. Nevertheless, there was no evidence for self-injury during reinstatement testing (presumably because of the small number of heroin doses administered) and there was no difference in heroin-induced reinstatement between LgA rats with self-injurious behavior and other LgA rats (Test 1 : Group: $\mathrm{F}(1,22)=0.21$; Group $\times$ Dose: $\mathrm{F}(3,66)=0.94$; Test 2 : Group: $\mathrm{F}(1,22)=1.23$; Group $\times$ Dose: $\mathrm{F}(3,66)=1.95)$.

\section{DISCUSSION}

The present study shows that the large majority of rats (ie, $\sim 90 \%$ ) with limited access to heroin self-administration (ShA rats) failed to respond to the priming effects of heroin, as measured in a within-session reinstatement model of drug-induced craving and relapse (Weiss et al, 2001; See et al, 2003; Shaham et al, 2003). In contrast, most of the rats (ie, 90\%) with escalating heroin use (LgA rats) showed a dramatic responsiveness to the reinstating effects of heroin. Importantly, this increased responsiveness was not owing to an increased sensitivity to the psychomotor effects of heroin. In fact, $\operatorname{LgA}$ rats tended to be less sensitive than ShA rats to these effects. Finally, 50\% of LgA rats continued to take heroin despite developing self-injury, a negative consequence not seen in ShA rats. This study reproduces and extends previous research on compulsive cocaine use by demonstrating that responding to the priming effects of heroin is also specific to compulsive drug use and dissociable from heroin reward and sensitization (Sutton et al, 2000; Mantsch et al, 2004; Ahmed and Cador, 2006).

As expected, during reinstatement testing, intravenous heroin produced a dose-dependent stimulation of forward locomotion. However, this dose-effect function was slightly shifted to the right in $\operatorname{LgA}$ rats compared to ShA rats, suggesting that the former are less sensitive, not more sensitive, than the latter to the stimulant effects of heroin. This rightward shift is unlikely the consequence of increased heroin-induced sedation or motor stereotypy as LgA rats responded more than ShA rats on the heroinassociated lever during reinstatement testing (see below). Moreover, although half of LgA rats developed self-injury during long-access sessions of heroin self-administrationa direct consequence of opiate-induced oral stereotypy (Pollock and Kornetsky, 1989) - this maladaptive behavior was not seen during reinstatement testing. In fact, $\operatorname{LgA}$ rats with self-injurious behavior did not differ from other LgA rats during reinstatement testing (not shown). Finally, in the present study, rats were tested after a brief withdrawal period from prolonged heroin self-administration (ie, $24 \mathrm{~h}$ ). It is possible that with longer periods of withdrawal, LgA rats would have become as sensitive as (or perhaps even more sensitive than) ShA rats to the psychomotor effects of heroin (Fernandes et al, 1977; Vasko and Domino, 1978; Vanderschuren et al, 1997; Timar et al, 2005). Future studies are needed to test this prediction. Nevertheless, in our previous study with cocaine self-administration, increasing the length of the withdrawal period (from 1 day to 2 weeks) did not modify the locomotor effects of cocaine in both ShA and LgA rats (Ahmed and Cador, 2006). In addition, the present study was designed to search for behavioral correlates of escalating heroin use, not of persistent vulnerability to relapse after protracted abstinence. Overall, this study reproduces and extends previous research on cocaine self-administration showing that psychomotor sensitization is poorly correlated with compulsive drug consumption (Ben-Shahar et al, 2004; Ahmed and Cador, 2006; Ferrario et al, 2005).

In contrast, during reinstatement testing after extinction, only $\operatorname{LgA}$ rats, not ShA rats, responded to the priming effects of heroin, as assessed in a within-session reinstatement procedure. Heroin-induced reinstatement was measured on two occasions during the maintenance of heroin self-administration, each time after $24 \mathrm{~h}$ of withdrawal. Regardless of the dose tested and of the reinstatement tests, heroin failed to reinstate heroin-seeking behavior in the vast majority of ShA rats whereas it concurrently produced 
a significant dose-dependent stimulation of forward locomotion. Thus, although able to induce locomotion and to reward lever pressing, heroin did not acquire the ability to instigate drug seeking in ShA rats. In contrast, in most LgA rats, heroin acquired powerful and robust priming properties. The prevalence of heroin responders in the LgA group (about 90\%) was significantly greater than the prevalence of responders in the ShA group (about 10\%). The very low prevalence of heroin responders in the ShA condition demonstrates that the rewarding effects of the drug can be dissociated from its priming properties, a dissociation that reproduces previous findings in rats with differential access to i.v. cocaine self-administration (Ahmed and Cador, 2006). A similar dissociation has also been previously reported in rats with the same daily duration of access to cocaine self-administration but with spontaneously low $v s$ high levels of cocaine consumption (Sutton et al, 2000; Baker et al, 2001). In these studies, cocaine or amphetamine induced a robust reinstatement of cocaine-seeking behavior in rats with high cocaine intake but had no effect in rats with low cocaine intake. The lack of reinstatement in the latter rats further demonstrates that some animals can selfadminister cocaine on a regular basis - thus showing sensitivity to the rewarding effects of cocaine-without becoming responsive to its priming effects.

At first glance, the lack of reinstatement of heroin-seeking behavior in ShA rats seems to contrast with most previous studies in the field. This apparent discrepancy may result from a combination of different procedural factors. First, in previous studies, daily access time to heroin was longer than the minimum of the present study (ie, $1 \mathrm{~h}$ ) and ranged between 2 and $12 \mathrm{~h}$, with $3 \mathrm{~h}$ being the most frequent duration of access (eg, de Wit and Stewart, 1981; Stewart and Wise, 1992; Shaham and Stewart, 1995; De Vries et al, 1998; Fuchs and See, 2002; Fattore et al, 2003; Leri et al, 2004; Luo et al, 2004; Yao et al, 2005). Thus, together with the present findings, this difference may point to the existence of some threshold duration below which most individuals readily learn to take heroin without becoming responsive to its priming effects and above which they begin to respond to these effects. Second, in most, except a few, previous studies, responding during reinstatement testing was followed by discrete stimuli that were originally paired with heroin injections (eg, de Wit and Stewart, 1981; Stewart and Wise, 1992; Shaham and Stewart, 1995; Fattore et al, 2003; Leri et al, 2004; Luo et al, 2004; Yao et al, 2005) whereas in the present study, no programmed responsecontingent cues were available during reinstatement testing. As drugs of abuse can dramatically increase responding for both unconditioned and conditioned sensory stimuli in drug-naïve animals (eg, Berlyne, 1969; Gomer and Jakubczak, 1974; Robbins, 1976; Robbins and Koob, 1978), this factor could also have contributed to the specific outcome of the present study. In support of this interpretation, Shelton and Beardsley (2005) have recently shown that omission of response-contingent stimuli during testing abolishes stress-induced reinstatement of cocaine-seeking behavior in rats with limited access to the drug $(2 \mathrm{~h} /$ day $)$. Whether the permissive effect of response-contingent cues on reinstatement depends on mere sensory reinforcement (ie, Berlyne, 1969; Tapp, 1969; Gomer and Jakubczak, 1974) and/or drug conditioning is unknown at present. Never- theless, in view of this effect, it is possible that drug-induced reinstatement is crucially dependent on response-contingent cues in ShA rats but becomes independent of these cues in LgA rats after the transition to compulsive drug use. Future research is needed to test this hypothesis.

Previous cross-reinstatement studies between different drugs have shown that drug-exposed, but non-sensitized, animals fail to respond to the reinstating effects of cocaine or heroin, suggesting that psychomotor sensitization is necessary for drug-induced reinstatement of drug seeking (De Vries et al, 1998, 1999; but see, Leri and Stewart, 2001). Our data suggest, however, that psychomotor sensitization is probably neither necessary nor sufficient for reinstatement of drug seeking after the transition to compulsive drug use (Ahmed and Cador, 2006; present study). Other neuroadaptative processes must thus intervene to explain why only animals with prolonged access to the drug become responsive to its priming effects. According to the reward allostatis hypothesis of drug addiction, prolonged access to the drug recruits brain anti-reward neurotransmitters that oppose the primary rewarding effects of the drug (Koob and Le Moal, 2001). During acute drug withdrawal, this counteradaptive process produces a transient decrease in brain reward function that slowly returns to normal (Barr and Markou, 2005). With repeated drug withdrawal, however, the counteraction would summate, thereby persistently shifting downward brain reward function (Koob and Le Moal, 2001). This allostatic decrease in brain reward function was recently demonstrated in rats with prolonged, but not limited, access to cocaine self-administration and was hypothesized to explain why addicted individuals neglect non-drug rewards in favor of drug use (Ahmed et al, 2002; Ahmed, 2005). Recently, using a computer simulation approach, we showed that this reward deficit would drive drug intake escalation by concurrently inducing a tolerance to, and an increased motivation, for the rewarding effects of the drug (Ahmed and Koob, 2005). Although there is as yet no direct neurobiological evidence for reward allostasis in animals with compulsive heroin use, the abnormal arrest of body growth seen in these rats in the present study may reflect, at least partly, decreased reward from food. This hypothesis is supported by a recent study showing that unlimited access to heroin self-administration is associated with a profound alteration in feeding (Chen et al, 2006), a phenomenon seen also in human opiate addicts (Santolaria-Fernandez et al, 1995). We speculate that an allostatic decrease in reward function may also explain why a drug (cocaine or heroin) acquires the ability to reinstate drug seeking only in compulsive drug users. Future theoretical and empirical research is needed, however, to define the exact neurobehavioral mechanisms of this selective acquisition.

Several methodological issues should be considered in interpreting the present data. First, ShA rats earned very few infusions, and as a saline and/or inactive lever control condition were not used, it cannot be ascertained that the available dose of heroin $(15 \mu \mathrm{g} /$ injection $)$ was rewarding for these rats in the present study. In a previous, unpublished study aimed at validating our self-administration procedure, however, we showed that when ShA rats $(n=11)$ had access to both an active lever (paired with the heroin dose used in the present study) and an inactive lever, they quickly learned to discriminate between the two levers (ie, 
within a week) (SH Ahmed, unpublished results; for similar results obtained in a different self-administration setting, see Ahmed et al, 2000). Another potential concern with the present study is that different doses of heroin were used for ShA rats $(15 \mu \mathrm{g})$ and $\mathrm{LgA}$ rats $(15 \mu \mathrm{g}$ for the first hour and $60 \mu \mathrm{g}$ for the last $5 \mathrm{~h}$ ) on maintenance days. This procedure was used to speed up escalation of heroin intake by $\operatorname{LgA}$ rats (Mantsch et al, 2004). However, it has the disadvantage of confounding dose with time of access. As a result, it is difficult to know whether LgA rats showed greater reinstatement effects than ShA rats because they had access to a higher dose of heroin or to a longer session of selfadministration. Nevertheless, current evidence favors the latter explanation. Results similar to those of the present study were reported in previous studies where both ShA rats and LgA rats had access to the same drug dose (Ahmed et al, 2000; Ahmed and Cador, 2006). For instance, despite having access to the same unit dose of cocaine on maintenance days, only LgA rats, but not ShA rats, were responsive to the priming effects of cocaine during reinstatement testing (Ahmed and Cador, 2006). This latter finding shows that differences in access time are sufficient to explain differences in drug-induced reinstatement between ShA rats and LgA rats. Finally, during reinstatement testing, $\operatorname{LgA}$ rats were lighter than ShA rats owing to a suppression of body growth. Theoretically, this difference in body weight should result in different brain heroin levels following administration of the same absolute doses (Wilkinson, 2001). This factor may have contributed to the difference in responsiveness to the priming effects of heroin observed between ShA rats and LgA rats. Nevertheless, the complete lack of reinstatement of drug seeking seen in ShA rats even at the highest dose of heroin indicates that this factor is probably not an important one. In addition, regardless of the group, there was no significant negative or positive correlation between body weight and performance during reinstatement testing in the present study $\left(r^{2}<0.14\right)$.

In summary, together with previous findings (Ahmed and Cador, 2006), the present study shows that drug-induced reinstatement is specific to compulsive drug use and dissociable from drug reward and psychomotor sensitization. We speculate that the ability of the drug to induce reinstatement of drug seeking is somehow related to the profound decrease in reward function that is selectively induced by prolonged, but not limited, access to drug selfadministration (Ahmed et al, 2002, 2005).

\section{ACKNOWLEDGEMENTS}

This work was supported by grants (to SHA) from Université Victor-Segalen Bordeaux 2, CNRS, MILDT and Région Aquitaine. Magalie Lenoir was supported by her parents, Catherine Ferrandière and Jean-Jacques Lenoir. We thank Stéphane Lelgouach and Anne Fayoux for animal care, Pierre Gonzalez for technical assistance, and Drs Luis Stinus and Martine Cador for excellent laboratory management and general support. We also thank Dr Yavin Shaham for bringing to our attention the work by Keith Shelton and Patrick Beardsley, and Pr Grant Wilkinson for pharmacokinetics suggestions. Finally, we thank the reviewers for their constructive comments.

\section{REFERENCES}

Ahmed SH (2005). Imbalance between drug and non-drug reward availability: a major risk factor for addiction. Eur J Pharmacol 526: 9-20.

Ahmed SH, Cador M (2006). Dissociation of psychomotor sensitization from compulsive cocaine consumption. Neuropsychopharmacology 31: 563-571.

Ahmed SH, Kenny PJ, Koob GF, Markou A (2002). Neurobiological evidence for hedonic allostasis associated with escalating cocaine use. Nat Neurosci 5: 625-626.

Ahmed SH, Koob GF (1998). Transition from moderate to excessive drug intake: change in hedonic set point. Science 282: 298-300.

Ahmed SH, Koob GF (1999). Long-lasting increase in the set point for cocaine self-administration after escalation in rats. Psychopharmacology 146: 303-312.

Ahmed SH, Koob GF (2005). Transition to drug addiction: a negative reinforcement model based on an allostatic decrease in reward function. Psychopharmacology 180: 473-490.

Ahmed SH, Lin D, Koob GF, Parsons LH (2003). Escalation of cocaine self-administration does not depend on altered cocaineinduced nucleus accumbens dopamine levels. J Neurochem 86: 102-113.

Ahmed SH, Lutjens R, van der Stap LD, Lekic D, Romano-Spica V, Morales $\mathrm{M}$ et al (2005). Gene expression evidence for remodeling of lateral hypothalamic circuitry in cocaine addiction. Proc Natl Acad Sci USA 102: 11533-11538.

Ahmed SH, Walker JR, Koob GF (2000). Persistent increase in the motivation to take heroin in rats with a history of drug escalation. Neuropsychopharmacology 22: 413-421.

Baker DA, Tran-Nguyen TL, Fuchs RA, Neisewander JL (2001). Influence of individual differences and chronic fluoxetine treatment on cocaine-seeking behavior in rats. Psychopharmacology 155: 18-26.

Barr AM, Markou A (2005). Psychostimulant withdrawal as an inducing condition in animal models of depression. Neurosci Biobehav Rev 29: 675-706.

Ben-Shahar O, Ahmed SH, Koob GF, Ettenberg A (2004). The transition from controlled to compulsive drug use is associated with a loss of sensitization. Brain Res 995: 46-54.

Berlyne DE (1969). The reward value of light increment under supranormal and subnormal arousal. Can J Psychol 23: 11-23.

Bozarth MA, Wise RA (1985). Toxicity associated with long-term intravenous heroin and cocaine self-administration in the rat. J Am Med Assoc 254: 81-83.

Caine SB, Lintz R, Koob GF (1993). Intravenous drug-selfadministration techniques in animals. In: Sahgal A (ed). Behavioural Neuroscience: A Practical Approach, Vol. 2. Oxford University Press: New York. pp 117-143.

Chen SA, O'dell LE, Hoefer ME, Greenwell TN, Zorrilla EP, Koob GF (2006). Unlimited access to heroin self-administration: independent motivational markers of opiate dependence. Neuropsychopharmacology, in press.

De Vries TJ, Schoffelmeer AN, Binnekade R, Mulder AH, Vanderschuren LJ (1998). Drug-induced reinstatement of heroin- and cocaine-seeking behaviour following long-term extinction is associated with expression of behavioural sensitization. Eur J Neurosci 10: 3565-3571.

De Vries TJ, Schoffelmeer AN, Binnekade R, Vanderschuren LJ (1999). Dopaminergic mechanisms mediating the incentive to seek cocaine and heroin following long-term withdrawal of IV drug self-administration. Psychopharmacology 143: 254-260.

de Wit H, Stewart J (1981). Reinstatement of cocaine-reinforced responding in the rat. Psychopharmacology 75: 134-143.

Deneau G, Yanagita T, Seevers MH (1969). Self-administration of psychoactive substances by the monkey. Psychopharmacologia 16: $30-48$. 
Fattore L, Spano MS, Cossu G, Deiana S, Fratta W (2003). Cannabinoid mechanism in reinstatement of heroin-seeking after a long period of abstinence in rats. Eur J Neurosci 17: $1723-1726$.

Fernandes M, Kluwe S, Coper H (1977). Quantitative assessment of tolerance to and dependence on morphine in mice. Naunyn Schmiedebergs Arch Pharmacol 297: 53-60.

Ferrario CR, Gorny G, Crombag HS, Li Y, Kolb B, Robinson TE (2005). Neural and behavioral plasticity associated with the transition from controlled to escalated cocaine use. Biol Psychiatry 58: 751-759.

Fuchs RA, See RE (2002). Basolateral amygdala inactivation abolishes conditioned stimulus- and heroin-induced reinstatement of extinguished heroin-seeking behavior in rats. Psychopharmacology 160: 425-433.

Gomer FE, Jakubczak LF (1974). Dose-dependent selective facilitation of response-contingent light-onset behavior by d-amphetamine. Psychopharmacologia 34: 199-208.

Heyne A, Wolffgramm J (1998). The development of addiction to d-amphetamine in an animal model: same principles as for alcohol and opiate. Psychopharmacology 140: 510-518.

Johanson CE, Balster RL, Bonese K (1976). Self-administration of psychomotor stimulant drugs: the effects of unlimited access. Pharmacol Biochem Behav 4: 45-51.

Kalivas PW (2005). How do we determine which drug-induced neuroplastic changes are important? Nat Neurosci 8: 1440-1441.

Koob GF, Le Moal M (2001). Drug addiction, dysregulation of reward, and allostasis. Neuropsychopharmacology 24: 97-129.

Koob GF, Sanna PP, Bloom FE (1998). Neuroscience of addiction. Neuron 21: 467-476.

Leri F, Stewart J (2001). Drug-induced reinstatement to heroin and cocaine seeking: a rodent model of relapse in polydrug use. Exp Clin Psychopharmacol 9: 297-306.

Leri F, Tremblay A, Sorge RE, Stewart J (2004). Methadone maintenance reduces heroin- and cocaine-induced relapse without affecting stress-induced relapse in a rodent model of poly-drug use. Neuropsychopharmacology 29: 1312-1320.

Liu Y, Roberts DC, Morgan D (2005). Effects of extended-access self-administration and deprivation on breakpoints maintained by cocaine in rats. Psychopharmacology 179: 644-651.

Luo F, Xi ZX, Wu G, Liu C, Gardner EL, Li SJ (2004). Attenuation of brain response to heroin correlates with the reinstatement of heroin-seeking in rats by fMRI. Neuroimage 22: 1328-1335.

Mantsch JR, Ho A, Schlussman SD, Kreek MJ (2001). Predictable individual differences in the initiation of cocaine self-administration by rats under extended-access conditions are dosedependent. Psychopharmacology 157: 31-39.

Mantsch JR, Yuferov V, Mathieu-Kia AM, Ho A, Kreek MJ (2004). Effects of extended access to high versus low cocaine doses on self-administration, cocaine-induced reinstatement and brain mRNA levels in rats. Psychopharmacology 175: 26-36.

Paterson NE, Markou A (2003). Increased motivation for selfadministered cocaine after escalated cocaine intake. NeuroReport 14: 2229-2232.

Pollock J, Kornetsky C (1989). Evidence for the role of dopamine D1 receptors in morphine induced stereotypic behavior. Neurosci Lett 102: 291-296.

Robbins TW (1976). Relationship between reward-enhancing and stereotypical effects of psychomotor stimulant drugs. Nature 264: $57-59$

Robbins TW, Koob GF (1978). Pipradrol enhances reinforcing properties of stimuli paired with brain stimulation. Pharmacol Biochem Behav 8: 219-222.

Robinson TE, Berridge KC (1993). The neural basis of drug craving: an incentive-sensitization theory of addiction. Brain Res Rev 18: 247-291.

Roth ME, Carroll ME (2004). Sex differences in the escalation of intravenous cocaine intake following long-or short-access to cocaine self-administration. Pharmacol Biochem Behav 78: 199-207.
Santolaria-Fernandez FJ, Gomez-Sirvent JL, Gonzalez-Reimers CE, Batista-Lopez JN, Jorge-Hernandez JA, Rodriguez-Moreno F, et al (1995). Nutritional assessment of drug addicts. Drug Alcohol Depend 38: 11-18.

See RE, Fuchs RA, Ledford CC, McLaughlin J (2003). Drug addiction, relapse, and the amygdala. Ann NY Acad Sci $\mathbf{9 8 5}$ 294-307.

Shaham Y, Hope BT (2005). The role of neuroadaptations in relapse to drug seeking. Nat Neurosci 8: 1437-1439.

Shaham Y, Shalev U, Lu L, De Wit H, Stewart J (2003). The reinstatement model of drug relapse: history, methodology and major findings. Psychopharmacology 168: 3-20.

Shaham Y, Stewart J (1995). Stress reinstates heroin-seeking in drug-free animals: an effect mimicking heroin, not withdrawal. Psychopharmacology 119: 334-341.

Shelton KL, Beardsley PM (2005). Interaction of extinguished cocaine-conditioned stimuli and footshock on reinstatement in rats. Int J Comp Psychol 18: 154-166.

Stewart J, Wise RA (1992). Reinstatement of heroin self-administration habits: morphine prompts and naltrexone discourages renewed responding after extinction. Psychopharmacology 108: 79-84.

Sutton MA, Karanian DA, Self DW (2000). Factors that determine a propensity for cocaine-seeking behavior during abstinence in rats. Neuropsychopharmacology 22: 626-641.

Tapp JT (1969). Activity, reactivity and the behavior-directing properties of stimuli. In: Tapp JT (ed). Reinforcement and Behavior. Academic Press: New York and London. pp 146-177.

Timar J, Gyarmati Z, Furst Z (2005). The development of tolerance to locomotor effects of morphine and the effect of various opioid receptor antagonists in rats chronically treated with morphine. Brain Res Bull 64: 417-424.

Vanderschuren LJ, Everitt BJ (2004). Drug seeking becomes compulsive after prolonged cocaine self-administration. Science 305: 1017-1019.

Vanderschuren LJ, Tjon GH, Nestby P, Mulder AH, Schoffelmeer AN, De Vries TJ (1997). Morphine-induced long-term sensitization to the locomotor effects of morphine and amphetamine depends on the temporal pattern of the pretreatment regimen. Psychopharmacology 131: 115-122.

Vasko MR, Domino EF (1978). Tolerance development to the biphasic effects of morphine on locomotor activity and brain acetylcholine in the rat. J Pharmacol Exp Ther 207: 848-858.

Walker JR, Chen SA, Moffitt H, Inturrisi CE, Koob GF (2003). Chronic opioid exposure produces increased heroin self-administration in rats. Pharmacol Biochem Behav 75: 349-354.

Weiss F, Ciccocioppo R, Parsons LH, Katner S, Liu X, Zorrilla EP et al (2001). Compulsive drug-seeking behavior and relapse. Neuroadaptation, stress, and conditioning factors. Ann NY Acad Sci 937: 1-26.

Wilkinson GR (2001). Pharmacokinetics: the dynamics of drug absorption, distribution, and elimination. In: Hardman JG, Limbird LE, Gilman AG (eds). Goodman and Gilman's the Pharmacological Basis of Therapeutics, 10th edn. McGraw-Hill: New York. pp 3-30.

Wolffgramm J (1991). An ethopharmacological approach to the development of drug addiction. Neurosci Biobehav Rev 15 515-519.

Yao L, McFarland K, Fan P, Jiang Z, Inoue Y, Diamond I (2005). Activator of $G$ protein signaling 3 regulates opiate activation of protein kinase A signaling and relapse of heroin-seeking behavior. Proc Natl Acad Sci USA 102: 8746-8751.

Zernig G, Wakonigg G, Madlung E, Haring C, Saria A (2004). Do vertical shifts in dose-response rate-relationships in operant conditioning procedures indicate 'sensitization' to 'drug wanting'? Psychopharmacology 171: 349-351. 